\title{
Principal results of the inelastic seismic performance of a 17-story RC building located in the soft-soil area in Mexico City with normal-strength concrete and with high-strength concrete
}

\author{
J. A. Avila \\ Institute of Engineering, National University of Mexico (UNAM), Mexico
}

\begin{abstract}
The principal responses of the inelastic seismic performance of a 17-story reinforced concrete building located in the soft-soil of Mexico City, with normalstrength concrete $\left(\mathrm{f}^{\prime}{ }_{\mathrm{c}}=250 \mathrm{~kg} / \mathrm{cm}^{2}\right)$ and with high-strength concrete $\left(\mathrm{f}^{\prime}{ }_{\mathrm{c}}=700\right.$ $\mathrm{kg} / \mathrm{cm}^{2}$ ), are analyzed. The designs are made according to the 2004 Mexico City Building Code, RDF-04. The design results are compared, after making spectral modal dynamic analysis, as well as the non-linear responses from the step-bystep dynamic analysis with the SCT-EW record of the 1985 earthquakes. Use of high-strength concretes $\left(\mathrm{f}_{\mathrm{c}}^{\prime}>400 \mathrm{~kg} / \mathrm{cm}^{2}\right)$ in reinforced concrete columns improves a great deal its axial load strength, and, therefore, in front of actions where compression high loads predominate, its performance is very adequate. In every analyzed case, reviewing the shear forces, the corresponding strength is never reached; that is, there is always a reserve strength, which is larger in highstrength concrete buildings; for this case a bigger quantity of transverse reinforcement by confinement was required because the design conditions for transverse reinforcement must be more demanding as the $\mathrm{f}^{\prime}{ }_{\mathrm{c}}$ value increases.
\end{abstract}

\section{Introduction}

In this paper the principal results are resumed that show the most important aspects of the inelastic seismic performance of a 17-story RC building; it is designed with normal-strength concrete and high-strength concrete, according to the Concrete Norms of the 2004 Mexico City Building Code, RDF-04 [1]. The 
service (interstory drift angles do not exceed the permissible maximum limit, 0.012 ) and failure (given strengths to satisfy the ductility factor $\mathrm{Q}=3$ requirements) limit states are satisfied according to the Concrete and Seismic Norms. The structure is designed for the soft soil conditions (zone $\mathrm{III}_{\mathrm{b}}$ ) in Mexico City. For the design, the spectral modal dynamic seismic analysis is used, considering the elastic-lineal three-dimensional performance; the vibration periods, maximum lateral displacements, interstory drift angle, shear forces, design internal actions, and longitudinal and transverse reinforcements are compared. Based on these designs, the non-linear response is later determined by making step-by-step dynamic analysis in time history, using the SCT-EW record representative of soft soil and the larger damages zone during the 1985 September earthquake in Mexico City. The maximum local ductility in beams and columns is calculated, as well as the global ductility and the tendencies that the failure mechanics develop. Finally, conclusions and recommendations to follow in the practical design of this kind of structure are presented, regarding both concrete strength types.

\subsection{High-strength concretes}

Some of the mechanical properties of high strength concrete are different from conventional concrete. Due to this there are some doubts about whether the actual structural design procedures for conventional concretes should be used in high strengths ones. In the Concrete Norms of 2004 Mexico City Building Code (RDF-04), these kinds of concretes have a compressive strength $\mathrm{f}^{\prime}{ }_{\mathrm{c}}$ equal or bigger than $400 \mathrm{~kg} / \mathrm{cm}^{2}$ (40 MPa), with values of $\mathrm{f}^{\prime}{ }_{\mathrm{c}}$ until $700 \mathrm{~kg} / \mathrm{cm}^{2}$, except structures designed with a seismic performance factor $\mathrm{Q}=4$ and members under combined compressive axial load and bending that take part of frames resisting more than $50 \%$ of the seismic actions and in which design axial load, $\mathrm{P}_{\mathrm{u}}$, is greater than $0.2 \mathrm{P}_{\mathrm{RO}}$, where $\mathrm{P}_{\mathrm{RO}}$ is the design concentric load capacity; in this case only concretes with $\mathrm{f}^{\prime}{ }_{\mathrm{c}}$ until $550 \mathrm{~kg} / \mathrm{cm}^{2}(55 \mathrm{MPa})$ can be used. To design, the nominal strength $\mathrm{f}_{\mathrm{c}}=0.8 \mathrm{f}_{\mathrm{c}}{ }_{\mathrm{c}}$ should be used instead of $\mathrm{f}^{\prime \prime}{ }_{\mathrm{c}}=0.85 \mathrm{f}^{*}$. The Norms propose to use the following equation in order to obtain the modulus of the elasticity of high-strength concretes: $E_{c}=7700 \sqrt{f{ }^{\prime}}+163000\left(\mathrm{~kg} / \mathrm{cm}^{2}\right)$ or

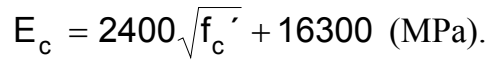

For design consideration purposes, under the combination of bending moment and axial load, many of the design procedures used for the conventional concretes have been applied and in most of cases good results have been obtained. Based on exhaustive experimental tests, a maximum allowable strain of $\varepsilon_{\mathrm{cu}}=0.003$ was adopted in conventional concrete design as a safe limiting value, but this is less conservative for high-strength concretes; the strain value in the concrete, $\varepsilon_{0}$, when it reaches the ultimate strength, is minor to high-strength concretes. The equivalent rectangular block of compression stress is proposed (ACI-318 and Concrete Norms of 2004 Mexico City Building Code), but its application in high-strength concrete members facing flexure without axial load and flexure with axial load has been questioned because a superior limit of $\mathrm{f}^{\prime}$, 
from which such block is invalid, has not been specified. The concrete ductility is going to diminish as long as the $\mathrm{f}^{\prime}{ }_{\mathrm{c}}$ value increases. High-strength concretes present typical stress-strain curves that can essentially be considered linear until the ultimate load, and after a fail suddenly shortly thereafter; in normal concretes, the stress-strain curve is curvilinear and the degradation of strength, from the ultimate load, is developed in a more gradual way. It can be observed that: 1) the lower the strength of concrete, the higher the failure strain, 2) the length of the initial relatively linear portion increases with the increase in the compressive strength of concrete, and 3) there is an apparent reduction in ductility with increase strength.

The transverse reinforcement increases the strength and ductility of a highstrength concrete column, but at a lower magnitude than the normal concrete due to the tendency of lateral deformations to be considerably smaller, which produces a less effective confinement. ACI-318 [2] recommends that the ratio of transverse reinforcement in columns, $\rho_{\mathrm{s}}$, will not be less than $3.1 \%$, with the purpose of the member being to present a reasonable ductility and the design equations being sufficiently conservative (see fig. 1). The quantity of confinement steel is directly proportional to the concrete strength and does not consider the axial load level in the structural element. Therefore, in members where the compressive strength of concrete $\left(\mathrm{f}^{\prime}{ }_{\mathrm{c}}\right)$ is high, we have a high ratio of transverse reinforcement, and in consequence construction problems; if the axial load is bigger than $0.40 \mathrm{P}_{\mathrm{RO}}$, the use of high-strength steel for the transverse reinforcement is recommended in order to attempt to avoid reinforcement congestion in the structure nodes. Despite the augmentation in concrete costs as its strength increases, the total cost of the structure will be less, because the concrete strength augmentation causes an important reduction in the structural element dimensions, as well as in the reinforcement areas. Some of the main parameters to consider in high-strength concretes are the following: a) workability, b) permeability, c) volumetric changes, and d) durability in useful life.

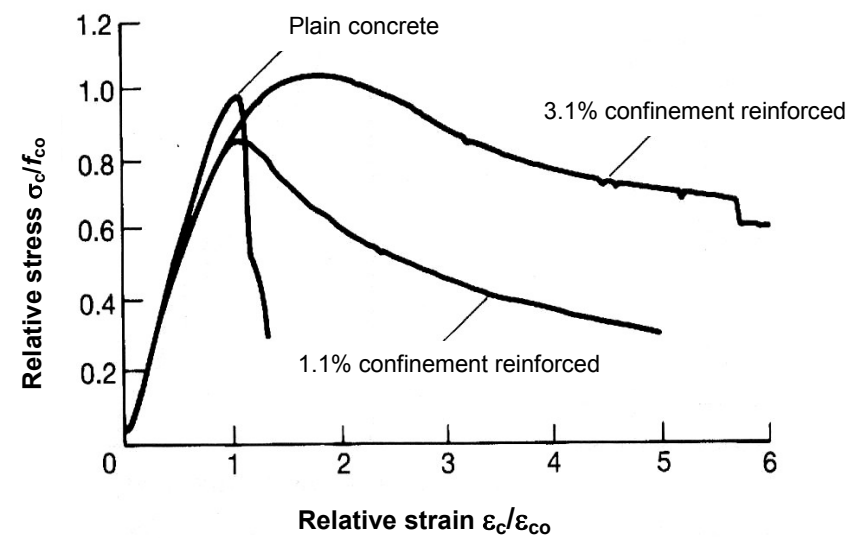

Figure 1: Confinement effects in the stress-strain curves of concrete. 
For the design of members subjected to flexure, it was assumed that the equivalent rectangular compressive stress block, despite the stress-strain curve of high-strength concretes, presents a performance that is sensitively different; the Codes require that the elements be under-reinforced, which implicates having a neutral axis at a low depth and very few zones of compression. The performance is dominated by tension steel and the form that acquires the rectangular compressive stress block is of little relevance. Nevertheless, in structural elements under compression axial load and flexure, the depth of the neutral axis, c, is larger, particularly when the axial load is high, and the flexure strength of the member depends sensitively on the form that acquires the compressive stress block. According to the obtained results in experimental tests of concrete, the equivalent rectangular compressive stress block gives acceptable results in the strength if $\mathrm{f}^{\prime}{ }_{c}$ is less than $55 \mathrm{MPa}\left(550 \mathrm{~kg} / \mathrm{cm}^{2}\right)$. According to test results of columns of high-strength concrete, when $\mathrm{f}_{\mathrm{c}}^{\prime} \leq 55 \mathrm{MPa}\left(550 \mathrm{~kg} / \mathrm{cm}^{2}\right)$, the elements can provide a ductile performance even with axial loads are elevated; in columns with $\mathrm{f}_{\mathrm{c}} \geq 55 \mathrm{MPa}$, submission to axial loads is low (approximately $0.2 \mathrm{P}_{\mathrm{R} 0}$ ), being designed with the requirements for columns of normal concrete, and they present a ductility that is acceptable; nevertheless, if the axial load increases it is necessary to have greater ratios of transverse reinforcement than those specified by the Codes. The expressions are the same as normal-strength concretes and do not establish a limit in the ratio of transverse reinforcement. Ghosh [3] recommends the use of transverse reinforcement of high strength, with a $\mathrm{f}_{\mathrm{y}}=82.5 \mathrm{MPa}$, in order to avoid reinforcement congestion and give the confinement required. To determine the shear strength of girders, the expressions of design of the actual Codes can give non-conservative results when $\mathrm{f}_{\mathrm{c}}>69$ MPa $\left(690 \mathrm{~kg} / \mathrm{cm}^{2}\right)$. In these cases, it is convenient to increase the development length or the ratio of transverse reinforcement, or to fix a minimum area of transverse reinforcement in the zone of unions and lap splices.

\section{Description of the building}

We consider a 17-story RC building with a ground level, basement and foundation box with point piles. Two cases are considered: A [normal-strength concrete with $\left.\mathrm{f}_{\mathrm{c}}^{\prime}=250 \mathrm{~kg} / \mathrm{cm}^{2}, \mathrm{E}_{\mathrm{c}}=14,000\left(\mathrm{f}_{\mathrm{c}}^{\prime}\right)^{1 / 2}=221,359 \mathrm{~kg} / \mathrm{cm}^{2}\right]$ and $\mathrm{B}$ [highstrength concrete with $\mathrm{f}_{\mathrm{c}}^{\prime}=700 \mathrm{~kg} / \mathrm{cm}^{2}, \mathrm{E}_{\mathrm{c}}=7,700\left(\mathrm{f}_{\mathrm{c}}^{\prime}\right)^{1 / 2}+163,000=366,723$ $\left.\mathrm{kg} / \mathrm{cm}^{2}\right]$. The concrete is class 1 with unit weight $\gamma_{\mathrm{c}}=2,400 \mathrm{~kg} / \mathrm{m}^{3}$; the reinforcement steel used has a yield stress $f_{y}=4,200 \mathrm{~kg} / \mathrm{cm}^{2}$. Fig. 2 shows the elevation and a typical floor of the 17-story building, for cases A and B. The floor system is concrete slab type of $10 \mathrm{~cm}$ thickness, cast in place with the girders and intermediate two-direction beams. The shape in plan of the floor slab diaphragm shall be as regular and symmetrical as possible, according to the requirements of Seismic Norms of the 2004 Mexico City Building Code, RDF-04.

\subsection{Design criteria}

For both cases the seismic design spectrum of soft-soil is considered (seismic zone $\mathrm{III}_{\mathrm{b}}$ ), according to the Seismic Norms of the 2004 Mexico City Building 

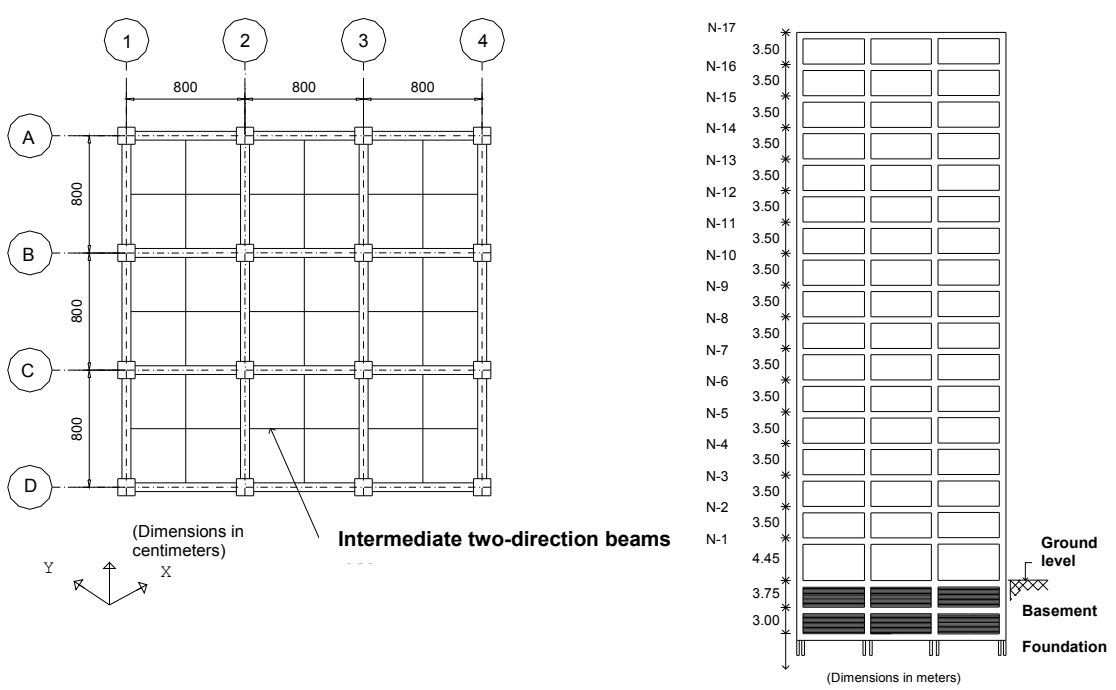

Figure 2: $\quad$ Elevation frame and typical floor plan, cases A and B.

Code, considering the ductility factor $\mathrm{Q}=3$ (see fig. 3). The reinforcement steel areas of the structural elements design (girders and columns) of cases A and B are determined with the last internal actions obtained from the structural analysis for the critical load combination, in accordance with the general requirements and ductile frames of the Concrete Norms. These designs include the load factor $\left(F_{c}\right)$ and the strength reduction factor $\left(F_{R}\right)$. The design of the reinforced concrete elements is accomplished with the general requirements and the ductile frame requirements of Concrete Norms, using ductility factor $\mathrm{Q}=3$. In the columns of the exterior frames (lines) of case $\mathrm{B}$, there are frequently dominated design values $\left[\mathrm{P}_{\mathrm{u}}, \mathrm{M}_{\mathrm{uM}}, \mathrm{M}_{\mathrm{um}}\right]$ with compression axial loads that are low or even axial tension loads. On the other hand, in the columns of interior frames in cases $\mathrm{A}$ and $\mathrm{B}$, the axial loads were of compression, and of considerable magnitude. The columns of the exterior frames for case B required greater longitudinal reinforcement. The 2004 Mexico City Building Code, RDF-04, proposes a strength-reduction factor $F_{R}=0.6$ for the design strength of axial compression with flexure (design I) when using the mechanical elements of structural analysis, and $F_{R}=0.9$ for the design strength of axial tension with flexure; the change of one state to another is given in an abrupt way. With the purpose of reviewing the previous work, for the columns of line A, we propose design II, similar to the ACI, with a strength-reduction factor $\left(F_{R}\right)$ increased from 0.6 to 0.9 , from the balanced strength. The reinforced concrete elements will have greater shear strength as the $\mathrm{f}^{\prime}{ }_{\mathrm{c}}$ increases. Using $\mathrm{f}^{\prime}{ }_{\mathrm{c}}=700 \mathrm{~kg} / \mathrm{cm}^{2}$ (case B), the ratio of transverse reinforcement will be superior; for this case it was not possible to limit the maximum spacing $\mathrm{s}=10 \mathrm{~cm}$, as done in case A. For the calculation of the shear reinforcement it the strength-reduction factor, $F_{R}=0.5$ was used; The Concrete Norms of the 2004 Mexico City Building Code, RDF04, specify that the shear strength of concrete, in order to show the 

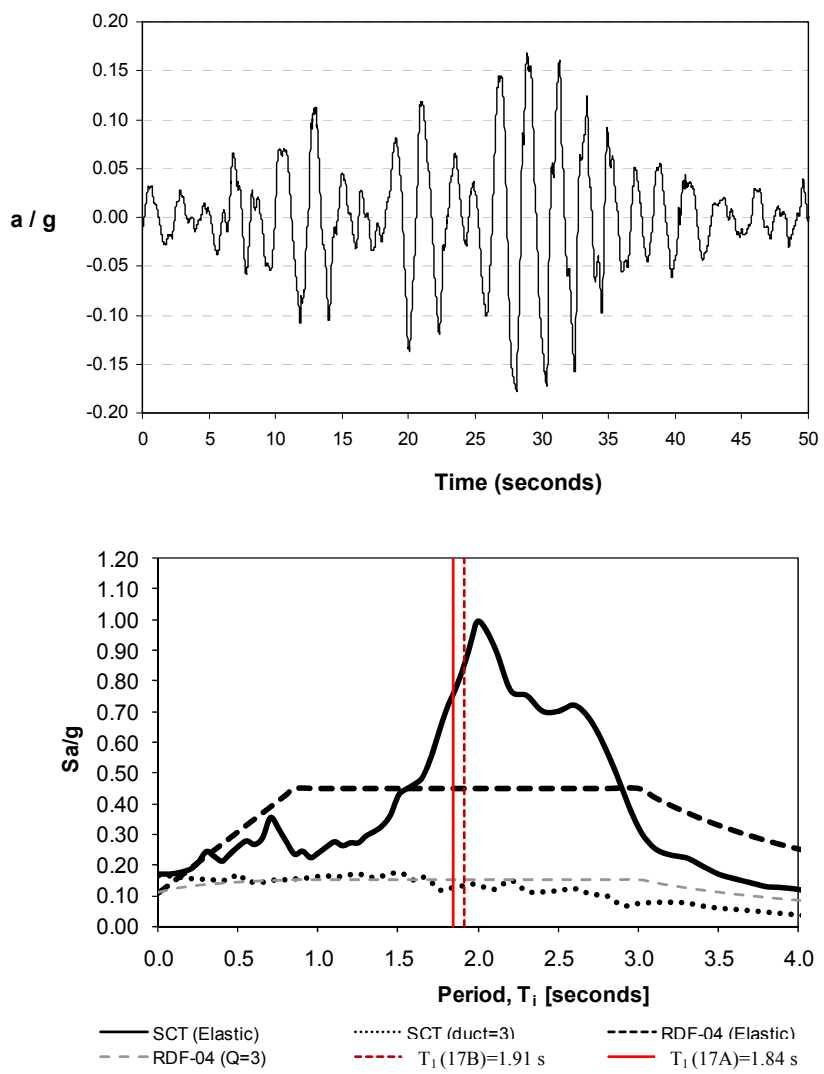

Figure 3: Time history SCT-EW of the 1985 Mexico City earthquake and location of the fundamental periods of vibration for cases A and B, regarding the design spectra and the response spectra of the SCTEW-85 record.

influence of the strength $\mathrm{f}_{\mathrm{c}}^{\prime}$, are: $\mathrm{V}_{\mathrm{CR}}=\mathrm{F}_{\mathrm{R}} \mathrm{bd}\left(0.2+20 \rho_{\mathrm{t}}\right) \mathrm{f}_{\mathrm{C}}^{*}$ if $\rho_{t}<0.015$ or $\mathrm{V}_{\mathrm{CR}}=0.5 \mathrm{~F}_{\mathrm{R}} \mathrm{bd} \sqrt{\mathrm{f}_{\mathrm{c}}^{*}}$ if $\rho_{t} \geq 0.015$, where $\mathrm{f}_{\mathrm{c}}^{*}=0.8 \mathrm{f}_{\mathrm{c}}^{\prime}$ and $\rho_{t}=$ the tension reinforcement ratio. In many columns of case $B\left(f^{\prime}{ }_{c}=700 \mathrm{~kg} / \mathrm{cm}^{2}\right)$, the necessary transverse reinforcement was dominated by the effects of the confinement of the concrete nucleus, which increased with high-strength concrete, as appreciated in the next equations of the Concrete Norms, where the maximum spacing of transverse reinforcement (vertical stirrups) is going to diminish as it increases $\mathrm{f}^{\prime}{ }_{\mathrm{c}}$ :

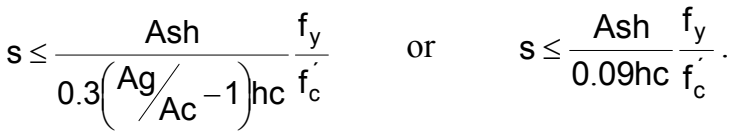




\section{Design elastic responses}

\subsection{Cross-section dimensions and weights}

The design dimensions of reinforced concrete girders and columns in case B are smaller; this reduction is more important in columns, so that the strength increase to compression in the concrete has a bigger influence in the performance of elements with high axial loads.

\subsection{Typical longitudinal and transverse reinforcement in columns and girders}

For the design of the column of line $A$, case A dominated $\left[\mathrm{P}_{\mathrm{u}}, \mathrm{M}_{\mathrm{uM}}, \mathrm{M}_{\mathrm{um}}\right]$ (factored axial load and factored bending moment about the major and minor axis), with the compression axial load $\mathrm{P}_{\mathrm{u}}$ and necessary longitudinal reinforcement of $16 \# 12+12 \# 10\left(277 \mathrm{~cm}^{2}\right)$; in the same column of line A and case $\mathrm{B}$ (design I), the axial load $\mathrm{P}_{\mathrm{u}}$ was of tension, and the necessary longitudinal reinforcement results $12 \# 12+20 \# 10\left(295 \mathrm{~cm}^{2}\right)$; for the same column of line A and case B, but design II, was $232 \mathrm{~cm}^{2}$. The columns of line B (internal) always dominated the loads combination under compression axial loads; the column of case A required $264 \mathrm{~cm}^{2}$, and for case B, $218 \mathrm{~cm}^{2}$. The spacing of transverse reinforcement that dominated was always the Code required in order to warranty the confinement of concrete nucleus, with a maximum spacing of $s=10 \mathrm{~cm}$. In the columns of line $\mathrm{A}$, for case $\mathrm{B}$, the design values frequently dominated $\left[\mathrm{P}_{\mathrm{u}}\right.$, $\left.\mathrm{M}_{\mathrm{uM}}, \mathrm{M}_{\mathrm{um}}\right]$, with compression axial loads, or even tension axial loads, low; in the columns of line $\mathrm{B}$, the axial loads were of compression. The longitudinal reinforcement of the columns of the frames of the same case gave similar results.

\subsection{Vibration periods}

Table 1 compares the vibration periods of the 17 -story RC building, cases A and B. The case B structure tends to be less rigid. Both cases fall near the dominant period of soil movement, $\mathrm{T}_{\mathrm{s}}=2$ seconds. The lateral performance of the building is symmetrical and regular.

Table 1: Vibration periods of the 17-story building, for cases A and B.

\begin{tabular}{|c|c|c|c|}
\hline \multirow{2}{*}{ Direction } & \multirow{2}{*}{ Mode } & \multicolumn{2}{|c|}{ Vibration periods, Ti [seconds] } \\
\cline { 2 - 4 } & & Case A & Case B \\
\hline \multirow{3}{*}{$\mathrm{X}=\mathrm{Y}$} & 1 & 1.84 & 1.91 \\
\cline { 2 - 4 } & 2 & 0.67 & 0.73 \\
\cline { 2 - 4 } & 3 & 0.39 & 0.42 \\
\hline \multirow{3}{*}{$\theta$} & 1 & 1.38 & 1.42 \\
\cline { 2 - 4 } & 2 & 0.53 & 0.55 \\
\cline { 2 - 4 } & 3 & 0.32 & 0.32 \\
\hline
\end{tabular}




\subsection{Maximum lateral displacements and interstory drift angle}

For this building, the serviceability limit state design predominates; it was not necessary to change the dimensions for structural members. In both design cases very similar responses are presented; the structure of the case B results was slightly more flexible. Case B presents responses that are slightly greater than the allowable limit, 0.012 .

\section{Inelastic seismic analysis}

Fig. 3 shows the time history SCT-EW of the 1985 Mexico City earthquake, used in the elastic and inelastic dynamic analysis. Fig. 3 presents, also, elastic and inelastic response spectra of the SCT-EW record (for a damping ratio of 5\% of critical), design spectra of RDF-04, and the location of the fundamental periods of vibration, for cases A and B. P- $\Delta$ effects were included and those of the dead and live loads; the structural frames of lines A (exterior) and B (internal) were examined. The elastic and inelastic dynamic analysis included strengths that were very large and strengths determined from the structural design, respectively, for comparative purposes. The bilinear elastoplastic hysteretic performance considers the steel strain hardening range, assumed a slope $3 \%$ for girders and $1.5 \%$ for columns, for cases $\mathrm{A}$ and $\mathrm{B}$. The required moment strength for girders accounts for the negative and positive moments, and for columns it accounts for the interaction diagrams moment-axial load (M-P).

\subsection{Global ductility demands and time history of roof lateral displacements}

Table 2 presents the global ductility demands $\left(\mu_{\mathrm{G}}\right)$ developed in each case. Generally, the inelastic response was smaller than the elastic. $\mu_{\mathrm{G}}$ of case A tends to be bigger; in none of the cases was the $\mu_{\mathrm{G}}$ greater than the design value, $\mathrm{Q}=3$. Inelastic lateral displacements of both cases are very similar; the lateral displacements of case B are slightly smaller. Case A presents greater differences regarding the elastic case, which implicates a greater non-linear performance.

\subsection{Interstory drift angle}

Fig. 4 presents the interstory drift angle for line B (internal) of the 17-story building, for cases $\mathrm{A}$ and $\mathrm{B}$. The inelastic response diminishes considerably regarding the elastic response, until reaching permissible level values; the case $\mathrm{A}$ responses tend to be bigger.

Table 2: $\quad$ Maximum demands of global ductility (for cases A and B).

\begin{tabular}{|c|c|c|c|c|c|c|}
\hline \multirow{3}{*}{ Line } & \multicolumn{6}{|c|}{ Clobal ductility demands $\left(\mu_{\mathrm{G}}\right)$} \\
\cline { 2 - 7 } & \multicolumn{3}{|c|}{ Case A } & \multicolumn{3}{c|}{ Case B } \\
\cline { 2 - 7 } & $\Delta_{\max }[\mathrm{cm}]$ & $\Delta_{\mathrm{y}}[\mathrm{cm}]$ & $\mu_{\mathrm{G}}$ & $\Delta_{\max }[\mathrm{cm}]$ & $\Delta_{\mathrm{y}}[\mathrm{cm}]$ & $\mu_{\mathrm{G}}$ \\
\hline $\mathrm{A}$ & 51.00 & 22.40 & 2.28 & 39.88 & 19.85 & 2.01 \\
\hline $\mathrm{B}$ & 48.98 & 18.50 & 2.65 & 38.36 & 18.84 & 2.04 \\
\hline
\end{tabular}




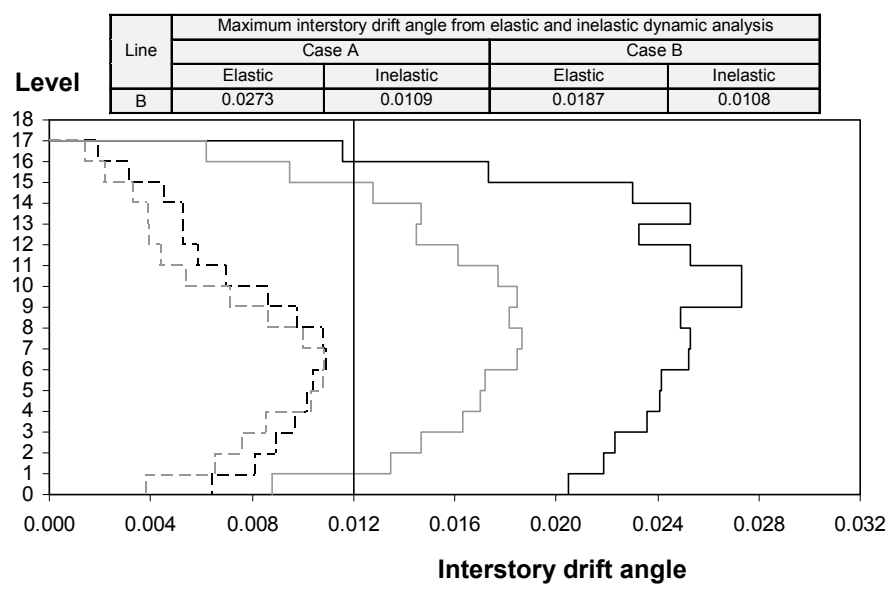

— Case A (elastic) - - - Case A (inelastic) _ Case B (elastic) - - Case A (inelastic)

Figure 4: $\quad$ Interstory drift angle for frame B from elastic and inelastic dynamic analysis under the SCT EW-85 record (for cases A and B).
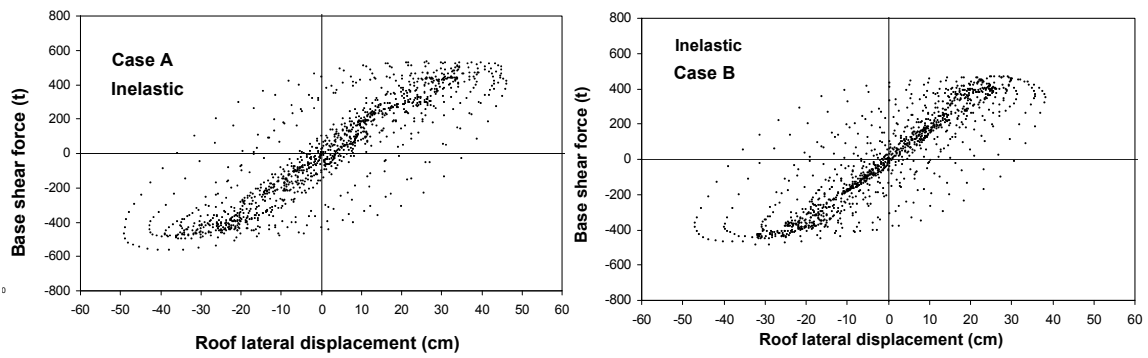

Figure 5: Curves of base shear force-roof lateral displacement for line B from inelastic dynamic analysis under the SCT EW record (for cases A and B).

\subsection{Curves of base shear force-roof lateral displacement}

Fig. 5 shows the curves of base shear force-roof lateral displacement. The response result is greater in case $\mathrm{A}$. The performance of frames $\mathrm{A}$ and $\mathrm{B}$, for cases $\mathrm{A}$ and $\mathrm{B}$, is similar to the structure symmetry. The elastic base shear for case $\mathrm{A}$ is approximately $50 \%$ greater. The responses of designs I and II of frame A, for case A, are similar.

\subsection{Maxima local ductility demands $\left(\mu_{\mathrm{L}}\right)$ developed in girders and columns, and global distribution of plastic hinges}

Fig. 6 compares the local ductility maximum demands $\left(\mu_{\mathrm{L}}\right)$ developed in the girders for line B, from inelastic dynamic analysis, for cases $\mathrm{A}$ and $\mathrm{B}$, for 


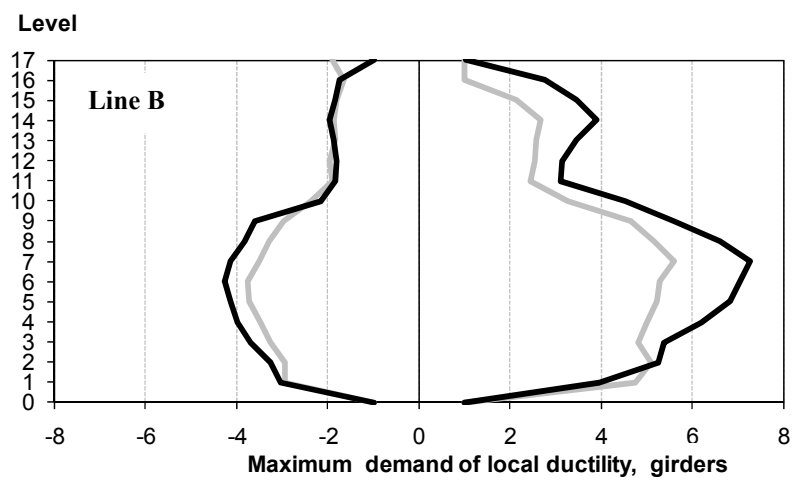

Case A Case B

Figure 6: Local ductility maximum demands developed in girders for line B from inelastic dynamic analysis under the SCT EW-85 record (for cases $\mathrm{A}$ and $\mathrm{B})$.

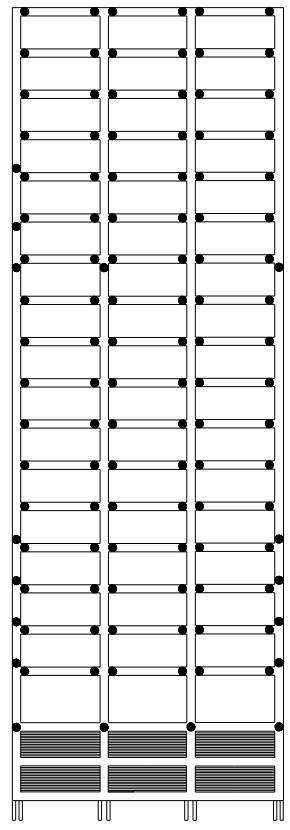

Line A, case A, design I

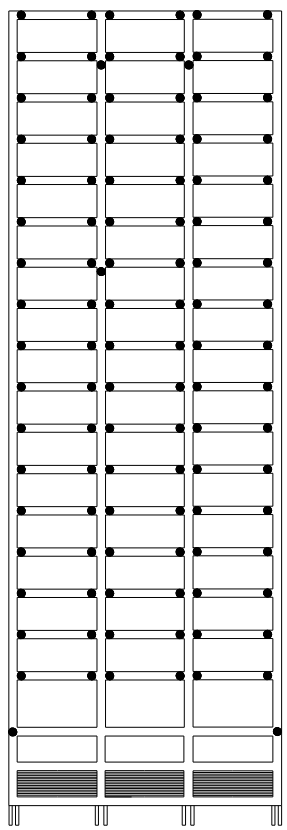

Line B, case A, design I

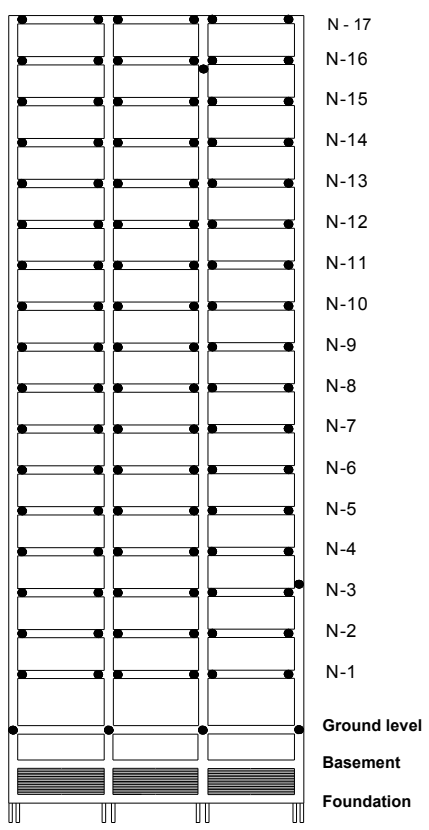

Line B, case B, design I

Figure 7: Global distribution of plastic hinges for lines A and B from inelastic dynamic analysis under the SCT EW-85 record (for cases $A$ and $B$, design $I$ with $F_{R}=0.6$ ). 
illustrative purposes. Girders maxima demands were rarely greater in case B for line $\mathrm{B}$. The $\mu_{\mathrm{L}}$ maxima values in girders, as in columns, are inside the admissible limits from the practical point of view. The local demands of columns tend to be very small, apart from the frame and case, which are greater in frame A. The columns of frame $A$ and case $B$, which were designed with a $F_{R}$ variable from 0.6 to 0.9 (design II), present demands that are hardly any greater, due to their minor strength. Figs. 7 and 8 show the global distributions of plastic hinges developed in girders and columns of the frames A and B, for cases A and B. The global distribution of plastic hinges presents a general tendency towards the failure mechanism known as "strong column-weak girder". This means that plastic hinges are in most parts of the girders and only in some columns, which is according to the actual design philosophy of the 2004 Mexico City Building Code. All girders of the exterior and interior frames (lines A and B) yield, and some columns of the exterior frame A, in particular the level inferiors. Case B for frame A with design II $\left(F_{R}\right.$ varies from 0.6 to 0.9$)$ presents a greater number of yields in columns, even in both ends of the elements; the columns of frame A were designed under axial loads that are very low, or even of tension, causing the values of $F_{R}$ to be close to 0.9 , giving as a result smaller longitudinal reinforcements.
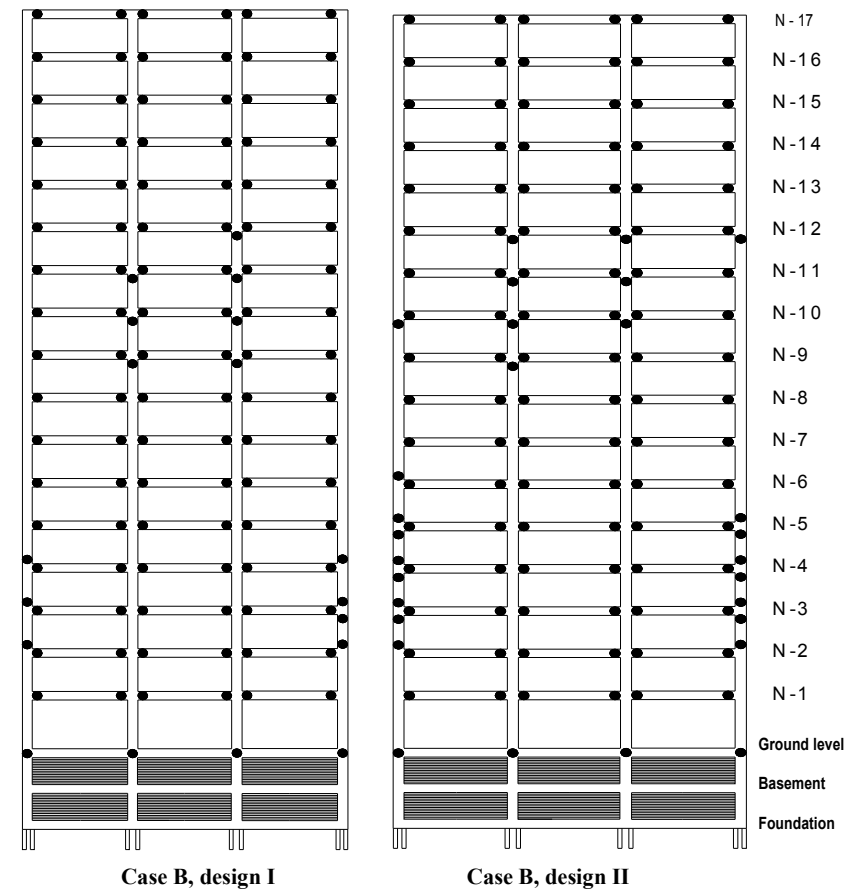

Figure 8: Global distribution of plastic hinges for line A from inelastic dynamic analysis under the SCT EW-85 record (for case B, design $\mathrm{I}, \mathrm{F}_{\mathrm{R}}=0.6$ and design II, $\mathrm{F}_{\mathrm{R}}=0.6$ to 0.9 ). 


\section{Conclusions}

The use of high-strength concretes $\left(\mathrm{f}_{\mathrm{c}}^{\prime}>400 \mathrm{~kg} / \mathrm{cm}^{2}\right)$ in reinforced concrete columns improves their axial load strength a great deal; where compression high axial loads predominate their performance is very adequate; nevertheless, in cases of lesser magnitude axial loads or even tensions, their use results in almost no change in efficiency, because the strength is given mainly by the reinforcement steel. Case A presents greater amplitude in the hysteretic cycles of the curves of basal shear force-roof lateral displacement, with a greater dissipated energy amount for inelastic deformations, according to the design philosophy "weak girder-strong column". The maxima values of local and global ductility demands are found to be inside those permissible by the 2004 Mexico City Building Code. In every analyzed case, reviewing the time histories of shear forces, the corresponding strength is never reached; that is, there is always a strength reserve, which is greater in the case B building, so that for this case a greater ratio of transversal reinforcement by confinement was required, because the design conditions for transverse reinforcement must be stricter as the $\mathrm{f}^{\prime}{ }_{\mathrm{c}}$ value increases. Use of high-strength concretes decreases the ductility in the elements under compression axial load and flexure (M-P), therefore the confinement steel should be larger. An alternative to avoid the congestion is the use of transverse reinforcement of high strength. High-strength concretes in structures located in seismic zones present some advantages regarding normalstrength concretes: they decrease the structure weight (the concrete volume of case B was 30\% less than normal), and decrease the ratios of longitudinal reinforcement, particularly in the interior frames, where the column performance is dominated by the compression axial load (the average reduction of weight of the longitudinal reinforcement steel of case B varies between $20 \%$ and $25 \%$ ). They have some disadvantages: the cost of high-strength concrete is greater, and tends to increase the ratio of transverse reinforcement (case B required a greater quantity of transverse reinforcement steel, due the confinement requirements). In zones with short seismicity, where the design in front of vertical loads dominates, use of high-strength concretes is more efficient; the concrete volume and ratios of reinforcement steel can be reduced in a substantial way.

\section{References}

[1] Gaceta Oficial del Gobierno de la ciudad de México, Reglamento de Construcciones del Distrito Federal, 2004.

[2] ACI 318-05, "Building Code Requirements for Structural Concrete", ACI 318-05, and Commentary, ACI 318R-05.

[3] Ghosh, S K, "High-strength concrete in U.S. Codes and Standards", XIV Congreso Nacional de Ingeniería Estructural, Sociedad Mexicana de Ingeniería Estructural, Acapulco, México, 2004. 